\title{
BRAULINO CAETANO DOS SANTOS, DOUTOR HONORIS CAUSA PELA UNIMONTES: O RECONHECIMENTO DE UM SABER QUE VEM DAS COMUNIDADES
}

\author{
Luciene Rodrigues ${ }^{1}$ https://orcid.org/0000-0002-3528-5574
}

\footnotetext{
${ }^{1}$ Doutora em História Econômica-USP e Pós-Doutora em Sociologia Econômica pela Universidade Nova de Lisboa. Professora Aposentada do Departamento de Economia-UNIMONTES. E-mail: lucienerodrigues.unimontes@gmail.com
}

\section{PREÂMBULO}

A Resolução Nº 015 do CONSU/2019² da Universidade Estadual de Montes Claros Unimontes concedeu o título de Doutor Honoris causa ao Ambientalista Braulino Caetano dos Santos. A Reitora em Exercício e Presidente em Exercício do CONSELHO UNIVERSITÁRIO (CONSU) da Universidade Estadual de Montes Claros (Unimontes), Professora ILVA RUAS ABREU, no uso das atribuições, e considerando: o disposto no inciso IV do artigo 167 e no artigo 168 e parágrafos do Regimento Geral; a sua memorável trajetória como empreendedor social, camponês e ambientalista de visão integrada aos problemas dos biomas e ecossistemas brasileiros; a sua participação primordial, decisiva e inquestionável como co-fundador do Centro de Agricultura Alternativa (CAA), da Cooperativa Grande Sertão, da Rede Cerrado e de cinco Associações Locais no Norte de Minas; o inestimável e relevante trabalho voltado para a preservação do meio ambiente e desenvolvimento sustentável, reconhecido como "Guardião do Cerrado; a sua atuação na formulação da Política Nacional de Desenvolvimento Sustentável de Povos e Comunidades Tradicionais (Decreto 6040 de março de 2007), onde assumiu a representação como Geraizeiro dos Povos do Cerrado na Comissão Nacional; que devido a sua prática social, tornou-se objeto de estudo e pesquisa acadêmica em diversas Universidades, principalmente pelo seu engajamento junto a outros atores e pela sua contribuição e protagonismo; o

${ }^{2}$ Disponível em: <https://unimontes.br/wp-content/uploads/2019/07/resolucao_consu015.pdf〉. Acesso em: jan. 2021. 
Braulino Caetano dos Santos, Doutor Honoris Causa pela Unimontes: o reconhecimento de um saber que vem das Comunidades

Luciene Rodrigues

reconhecimento pela sua contribuição na consolidação da agricultura alternativa no Norte do Estado de Minas Gerais; a aprovação do Conselho Universitário, em Sessão Plenária do dia 29 de maio de 2019, resolve: Art. $1^{\circ}$ CONCEDER o título de Doutor Honoris causa ao Ambientalista Braulino Caetano dos Santos.

\section{OBJETIVOS DO TÍTULO E FUNDAMENTOS FORMAIS PARA SUA ATRIBUIÇÃO}

O título Doutor Honoris Causa, isto é, Doutor "por causa de honra" é utilizado quando uma Universidade de prestígio deseja conceder um título de honra para uma personalidade de grande destaque ou importância por seu trabalho, mesmo que ela não tenha um curso universitário, mas tenha se destacado ou exercido grande influência em determinadas áreas, como nas artes, literatura, meio ambiente, política, no trabalho social ou promovendo a paz. O título constitui um reconhecimento de instituições acadêmicas a pessoas com saber e ações dedicadas à promoção humana, a problemas sociais como pobreza, fome, desenvolvimento comunitário, cuidado com os ecossistemas, direitos humanos e justiça social. O indivíduo recebe esse título pelo trabalho em prol dessas causas, por suas virtudes, méritos ou atitudes, recebendo tratamento como se tivesse feito um doutorado acadêmico convencional, podendo utilizar este título à frente de seu nome, Dr.h.c.

A Unimontes, em seu Regimento Geral, Art. 167, Inciso IV, assevera que: "A Universidade Estadual de Montes Claros - UNIMONTES - pode atribuir títulos: (...) IV - De Doutor Honoris Causa a personalidade que tenha se distinguido pelo saber ou pela atuação em prol das artes, das ciências, da filosofia, das letras, da administração pública, do bem-estar humano ou do melhor entendimento entre os povos". O Art. 168 assegura a qualquer membro do Conselho Universitário a prerrogativa de propor concessões de títulos.

\section{VIDA E ENGAJAMENTO DE BRAULINO CAETANO DOS SANTOS EM CAUSAS HONROSAS}

BRAULINO CAETANO DOS SANTOS é um camponês ambientalista engajado em causas sociais e na defesa dos ecossistemas, de reconhecido destaque com projeção regional, nacional e internacional, que tem um saber próprio, uma habilidade de construir processos, interagir com diferentes atores, perceber as questões de fundo, como a importância dos povos na proteção dos cerrados e não apenas das ONGs e do Estado. 
Braulino Caetano dos Santos, Doutor Honoris Causa pela Unimontes: o reconhecimento de um saber que vem das Comunidades

Luciene Rodrigues

Ele nasceu em 1946, na zona de chapadas entre Montes Claros e Bocaiúva, é casado, pai de quatro filhos. Como descreve a Professora do Departamento de Educação da UFMG, Augusto (2011), Braulino é agricultor familiar e liderança emergente no final da década de 1980, no campo das lutas ambientais e agroecológicas. Seu sítio, com mais de 10 hectares, fica na Comunidade de Abóboras, nas margens do Rio São Lamberto, afluente do Rio São Francisco. Trabalhou até os 26 anos como agregado na Fazenda vizinha a seu sítio atual. De trabalhador rural a agricultor familiar, contribui para o desenvolvimento territorial do Norte de Minas e do Brasil. Participou, do Sindicato dos Trabalhadores Rurais, do processo de sistematização da Constituição Federal de 1988, da criação da Rede Cerrado, da formulação da Política Nacional de Desenvolvimento Sustentável de Povos e Comunidades Tradicionais na ECO 92, onde assumiu a representação dos geraizeiros na Comissão Nacional, e foi uma personalidade importante na condução dos trabalhos durante a Rio+20 e posterior. Participou de Conferências e Encontros em Istambul (Turquia), Moçambique (África), Estados Unidos, Alemanha, Itália, Argentina, Jamaica, Paraguai, entre outros. Foi um dos idealizadores do Centro de Agricultura Alternativa, está no Conselho Diretor desde a sua criação, em 1985. Neste ano de 2019 o CAA completa 35 anos de existência e 30 anos de constituição jurídica, com atuação e ações voltadas para o desenvolvimento comunitário local, integrado e sustentável.

Sem oportunidade de frequentar a escola quando criança e jovem, Braulino aprendeu a ler e escrever já adulto, tem uma vida dedicada à construção de um modelo de desenvolvimento mais digno, justo, inclusivo e sustentável para todos. Para ele a educação é a verdadeira ferramenta da transformação social: "A juventude de hoje precisa estudar para o bem comum".

A prática social de Braulino Caetano tornou-se objeto de estudo e pesquisa acadêmica em diversas Universidades, pelo seu engajamento junto a outros atores, pela sua contribuição e protagonismo. Existem, assim, mais de uma dezena de Teses de Doutorado, Dissertações de Mestrado e Monografias sobre sua trajetória, conhecimentos, saberes e contribuição para o desenvolvimento local.

Entre suas práticas sociais, destacam-se a participação na Comissão da Constituinte de 1988 que garantiu uma série de Direitos Sociais aos agricultores; a criação do CAA; da Cooperativa Grande Sertão; da Rede Cerrado; no reconhecimento de identidades de povos tradicionais da região (Indígenas, Quilombolas, Veredeiros, Catingueiros, Geraizeiros, Apanhadores de flores), o que resultou na unificação de lutas de várias regiões do país e na 
Braulino Caetano dos Santos, Doutor Honoris Causa pela Unimontes: o reconhecimento de um saber que vem das Comunidades

Luciene Rodrigues

criação da Comissão Nacional dos Povos e Comunidades Tradicionais e de políticas públicas específicas; na definição da Política Estadual de Desenvolvimento Sustentado do estado de Minas Gerais; na criação de cinco Associações locais; na organização dos trabalhadores rurais e no Projeto de Curso de Formação em Agroecologia desde 1993, com cerca de 50 jovens/ano (o que totaliza a formação de aproximadamente 1.250 jovens em Agroecologia). Destas práticas, destacamos as seguintes:

a) Criação/fundação do CAA (Centro de Agricultura Alternativa do Norte de Minas), importante instituição voltada para o desenvolvimento local. Em 1985, durante um seminário realizado na cidade de Montes Claros, houve uma proposta de reconsiderar as economias locais e uma diversidade de sistemas culturais de produção associada. Foi então criado o Centro de Agricultura Alternativa do Norte de Minas - CAA-NM, sendo institucionalizado posteriormente, em 1989. O CAA-NM é voltado para o fortalecimento de questões socioambientais, preservação da cultura dos povos tradicionais, geração de emprego e renda para a agricultura familiar e preservação do ecossistema norte-mineiro. Como membro do Conselho Diretor, desde a sua fundação, Braulino Caetano contribui na organização e formação acadêmica de jovens agricultores, pesquisadores e estagiários de diversas Universidades do país e do Exterior (Unimontes, UFMG, UFV, UFL, UFJM, UFG, UNB, entre outras), de organizações voltadas para a Agricultura (EMBRAPA, EMATER, FAO, IICA). O CAA busca o conhecimento local e técnico para elaborar ferramentas e estratégias viáveis de desenvolvimento de modo sustentável, de ação colaborativa no intuito de promover o crescimento e o fortalecimento das comunidades, suas agriculturas e economias.

b) como Empreendedor Social, promotor da Economia Solidária e da Agroecologia, promove a criação da Cooperativa de Agricultores Familiares e Agroextrativista Grande Sertão. A Cooperativa Grande Sertão (CGS), nasceu de um sonho coletivo, desde 1995, sendo Braulino um dos idealizadores, que fez dela um laboratório de experimentação de diversos modelos, até se chegar à sua formalização em 2003. A Cooperativa possui em seu quadro social 186 associados, com sede em Montes Claros - MG, tendo como área de atuação 39 municípios do norte de Minas Gerais, envolvendo indiretamente cerca de 3 mil famílias de 350 comunidades rurais do norte de Minas. Algumas delas têm na Cooperativa uma importante fonte de renda. Além de dinamizar a economia das comunidades locais, a Cooperativa Grande Sertão contribuiu para a permanência dos agricultores no campo, permitindo, ao mesmo tempo, ampliar a renda familiar. A Cooperativa trabalha de modo a conviver com as adversidades climáticas (seca), luta pela preservação do Cerrado, extrativismo sustentável, segurança 
Braulino Caetano dos Santos, Doutor Honoris Causa pela Unimontes: o reconhecimento de um saber que vem das Comunidades

Luciene Rodrigues

alimentar e clima. Busca fortalecer iniciativas locais para garantir autonomia para as agroindústrias familiares. A Cooperativa Grande Sertão utiliza a metodologia de redes sociotécnicas, que envolve agricultores, técnicos, pesquisadores e professores, em diferentes cadeias produtivas. O cooperativismo tem como objetivo melhorar a vida dos associados, superar situações de exclusão especialmente dos pequenos produtores que procuram a inserção de seus produtos nos mercados. Inicialmente, a CGS começou com a produção de polpas em pequenas quantidades, armazenadas em um único freezer e entregues de bicicleta para os consumidores da cidade. Posteriormente, a marca Grande Sertão foi registrada, a embalagem constando tabela nutricional e data de fabricação, com cores e elementos que expressam as características dos produtos e os diferenciais sociais e ambientais da marca (produção agroecológica, regionalidade, inserção social e econômica dos agricultores familiares).

Atualmente a Cooperativa comercializa diversos produtos alimentícios, polpas de frutas nativas ou cultivadas, típicas do cerrado e da caatinga, mel, rapadura, cachaça, oleaginosas, farinha, mel, entre outros produtos. São mais de 18 variedades de polpa de frutos, além do óleo e polpa congelados de pequi (Caryocar brasiliense Camb). A Cooperativa conquistou, ao longo dos anos, distintos mercados e possibilita, dessa forma, que os produtos da agricultura familiar sejam reconhecidos por meio de sua marca e que os atores sociais envolvidos bem como a população da região tenham melhores condições de vida. A Cooperativa também articula a compra e venda de sementes de sorgo, milho, feijão e arroz, proporcionando o intercâmbio solidário de sementes crioulas entre as comunidades. As sementes saem dos assentamentos e comunidades rurais, são disponibilizadas para outras comunidades e circulam entre grupos de agricultores da região, que assumem o compromisso de preservar as variedades genéticas.

Desse modo a Cooperativa, reune agricultores e agroextrativistas da região com o intuito de receber, transportar, classificar, padronizar, armazenar, beneficiar, industrializar e comercializar produtos originados de seus cooperados, sendo in natura ou artesanais, por meio da produção e da disponibilização de insumos, bens de produção e, também, produtos de primeira necessidade aos associados. Visa à promoção do desenvolvimento social e econômico para que os seus associados tenham qualidade de vida, qualificação e assessoria técnica que leve em consideração a preservação do meio ambiente e a busca de alternativas econômicas dentro dos princípios agroecológicos que priorizem a produção orgânica e valores a ela associados. A CGS é, sem dúvida, um belo exemplo de inovação e empreendedorismo 
Braulino Caetano dos Santos, Doutor Honoris Causa pela Unimontes: o reconhecimento de um saber que vem das Comunidades

Luciene Rodrigues

social, sendo Braulino um dos atores chaves desse processo, que busca, pela valorização cultural, perpetuar as tradições da região e garantir, como princípios e estratégia para acessar os mercados, o trabalho nos valores que são ligados à sustentabilidade e cultura sertaneja. A luta pela sobrevivência e expansão da Cooperativa têm requerido motivação permanente diante das dificuldades de natureza econômica, contábil, jurídicas, fiscais, entre outras.

c) Pela Criação do Solar dos Sertões, em que cumpre destacar a participação de Braulino na aquisição, pelo CAA, do Casarão localizado no Conjunto Urbanístico da Praça Doutor Chaves, considerado um dos imóveis mais notáveis de Montes Claros, com seus traços finos, arquitetura singular, construído em 1856 e tombado em 1999 pelo Patrimônio Histórico do Município. Este espaço, denominado "Solar dos Sertões" agrega um Centro de Documentação, acolhe registros fotográficos e audiovisuais dos Povos e Comunidades Tradicionais, com suas histórias, saberes, pesquisas e estudos sobre a região Norte do Estado de Minas e, também o Empreendimento Solidário - Empório do Sertão - espaço de exposição e comercialização de produtos sertanejos e de promoção dos valores da gastronomia sertaneja, patrimônio cultural dos Povos e Comunidades da região.

O Empório do Sertão, situado no Casarão, intenta trazer a diversidade de produtos, fazeres e saberes dos povos e comunidades tradicionais sertanejas. Planejado para acolher uma arena artística, com o objetivo de evidenciar as expressões culturais dos geraizeiros, quilombolas, indígenas, catingueiros e vazanteiros, num diálogo entre as culturas tradicionais dos povos do sertão, campo e cidade para reforçar a identidade sociocultural do Norte de Minas.

d) Pela participação na criação da Rede Cerrado, movimento nacional de defesa do bioma e dos povos dos Cerrados brasileiros, com sede em Goiânia-Go.

e) Pela tessitura de redes sociais concretas por meio do CAA/NM e constituição de espaços de discussão de ações coletivas e políticas públicas no âmbito regional, estadual, nacional e internacional para promoção do desenvolvimento local, sustentável e integrado. Nesse sentido, pode-se citar o fomento ao trabalho em redes de organizações como ANA Articulação Nacional de Agroecologia, Rede Cerrado, Rede Alerta Contra o Deserto Verde, ASA - Articulação do Semiárido (Programa Um Milhão de Cisternas, Programa Uma Terra e Duas Águas), RESAB - Rede de Educadores do Semi-árido Brasileiro, AMA - Articulação Mineira em Agroecologia, FMSA - Fórum Mineiro de Segurança Alimentar e Nutricional, GT - Gênero/ANA - Região Sudeste, Fórum de Desenvolvimento Sustentável do Norte de Minas, Conselho Municipal de Segurança Alimentar, CRSAN - Comissão Regional de 
Braulino Caetano dos Santos, Doutor Honoris Causa pela Unimontes: o reconhecimento de um saber que vem das Comunidades

Luciene Rodrigues

Segurança Alimentar e Nutricional, CIAT - Comissão de Implantação das Ações Territoriais da Serra Geral e Alto Rio Pardo, CNDSPCT - Comissão Nacional de Desenvolvimento Sustentável de Povos e Comunidades Tradicionais, CONACER - Comissão Nacional do Programa Cerrado Sustentável, CONAFLOR - Comissão Coordenadora do Programa Nacional de Florestas, CONSEA NACIONAL - Conselho Nacional de Segurança Alimentar e Nutricional Sustentável, CONDRAF - Conselho Nacional de Desenvolvimento Rural Sustentável, CNES - Conselho Nacional de Economia Solidária

Todas essas ações envolvem uma série de atores sociais, entre eles Braulino Caetano é um sujeito chave na articulação, no trabalho cotidiano e não raro invisível.

\section{JUSTIFICATIVA ACADÊMICA PARA CONCESSÃO DO TÍTULO, ADERÊNCIA} ENTRE O PROPÓSITO DO TÍTULO E A TRAJETÓRIA DE VIDA DO AGRACIADO PROPOSTO E A PERTINÊNCIA DA UNIVERSIDADE NA CONSTRUÇÃO DE UM CONHECIMENTO PLURAL DE SABERES MÚLTIPLOS

A América Latina tem uma tradição em que os saberes acadêmicos entram em diálogo com os saberes da população, por meio do envolvimento dos investigadores, mas os saberes populares e indígenas não têm sido suficientemente reconhecidos pela Academia. Uma questão chave da teoria social neste final da segunda década do século XXI é a relação entre a produção de teoria e o saber dos sujeitos na ação, a relação entre si de saberes múltiplos, diante de um quadro de divisão entre saber racional (formalizado na teoria) e o saber informal (implícito) dos sujeitos nas práticas sociais. O grande desafio consiste em encontrar caminhos para requalificar as diferenças epistêmicas e rearticular estes diferentes elementos tradicionalmente separados. Reconhecer a existência de uma pluralidade de saberes, a importância das suas relações e promover a sua intersecção, é um ato de justiça epistêmica e social. Não há possibilidade de justiça social sem justiça epistêmica. Neste sentido, ao atribuir o título de Honoris Causa a Braulino Caetano, a Unimontes contribui para fazer justiça epistêmica.

Braulino Caetano é possuidor de um saber situado e situacionado (K. Mannheim), um saber notório acerca dos recursos naturais, bens comuns, relação sociedade-natureza, economia, coletivos culturais e coletivos sociais. Trabalha na construção de um modelo social com base na compreensão de que desenvolvimento é autodeterminação (assim como Darcy Ribeiro, Celso Furtado entre outros pensadores), valorização do ciclo ecoterritorial (bens comuns e território, justiça ambiental, viver bem, soberania alimentar, ética do cuidado) numa confluência de saberes, com outra racionalidade que envolve a questão ambiental, ecologia 
política, economia da proximidade, dos vínculos, de relações entre pessoas e meio e dos circuitos pequenos, na esteira de uma gramática de mudança, descolonial. Ele nos desafia a unir conhecimento ao mundo da vida, a agir na construção de um diálogo pluralista.

BRAULINO CAETANO DOS SANTOS é portador de uma trajetória de trabalho e engajamento social, é uma personalidade que faz jus ao título de causa honrosa, possuidor de um saber que merece nossa atenção, respeito e aplauso. A concessão do título pela Universidade constitui uma ação inovadora; uma valorização das práticas sociais; a construção de uma nova ponte, com comunicação nos dois sentidos para com as comunidades envolventes objeto de teses, dissertações, monografias; uma nova relação na produção do conhecimento, com base em saberes múltiplos. O reconhecimento de uma "ecologia de saberes", utilizando a nomenclatura de Boaventura de Souza Santos, significa o reconhecimento de que junto ao saber científico, o saber tradicional, popular, camponês é capaz de construir processos e práticas sociais promotoras do ambiente, dos territórios, da dignidade humana e das economias dos povos.

O reconhecimento desses saberes comporta um profundo sentido simbólico, mas, para além dele e, sobretudo, um profundo sentido ético e político sobre a vida social do entorno da Universidade. Conceder o título de Honoris Causa a Braulino Caetano significa reconhecer esse saber e as práticas sociais que lhe correspondem; significa para a Unimontes reconhecer uma cosmovisão, práticas sociais inovadores que constituem verdadeiros Laboratórios de Experimentação de outras economias na sociedade viva, num espaço que acontece, que se vai construindo, heterotrópico, carregado de significados culturais. Conceder esse título a Braulino Caetano é uma oportunidade de a Unimontes transitar e compreender a riqueza de outros tipos de saberes numa episteme ecológica, centrada no tecido da vida, com pensamento e ação de fronteira. 
Braulino Caetano dos Santos, Doutor Honoris Causa pela Unimontes:

o reconhecimento de um saber que vem das Comunidades

Luciene Rodrigues

Registros fotográficos da Concessão honorífica à Braulino Cetano em 24 de setembro de 2019.

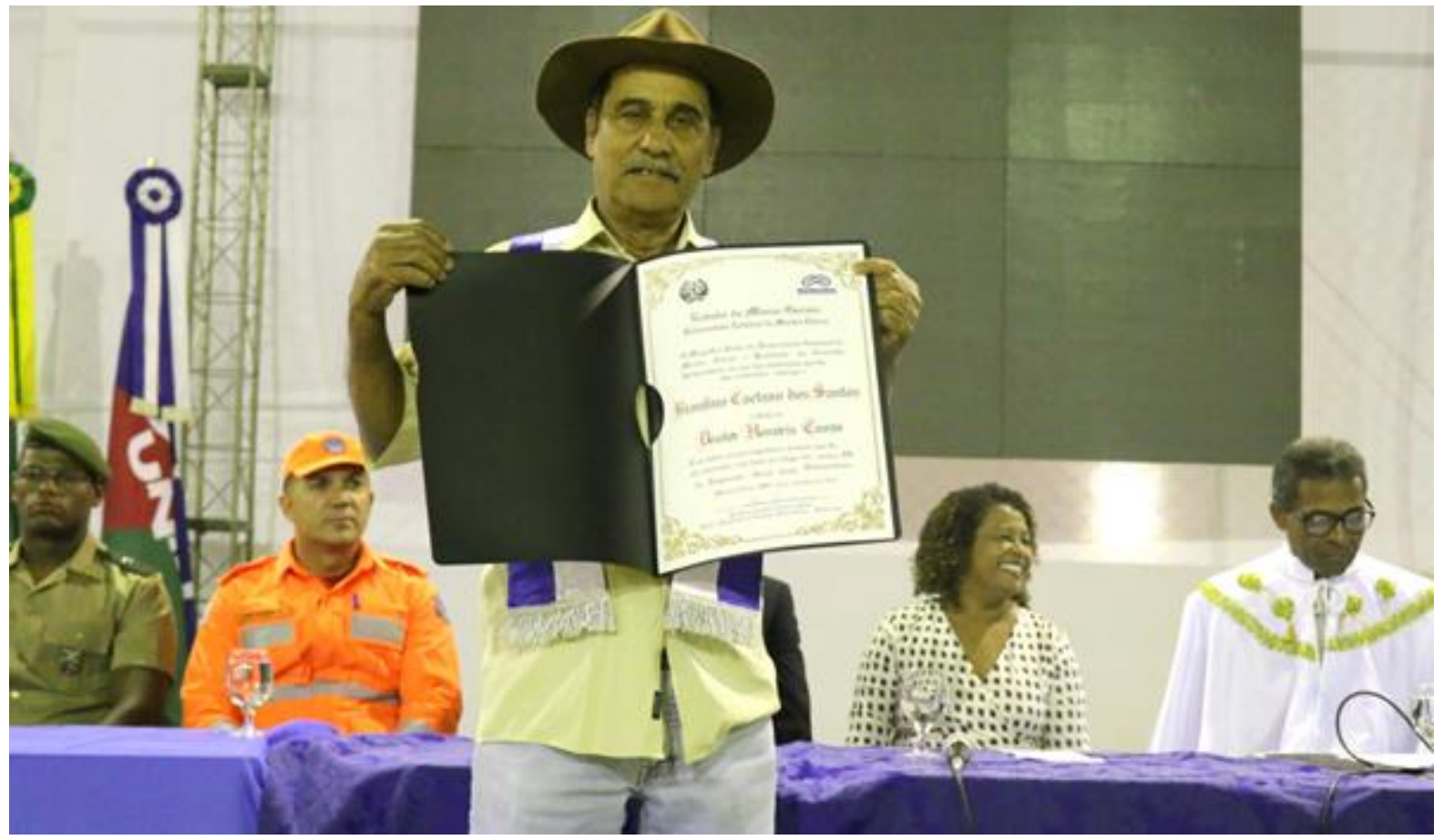

Braulino Caetano dos Santos é o novo Doutor Honoris Causa da Unimontes. Fotos: Christiano Jilvan - Ascom Unimontes $^{3}$

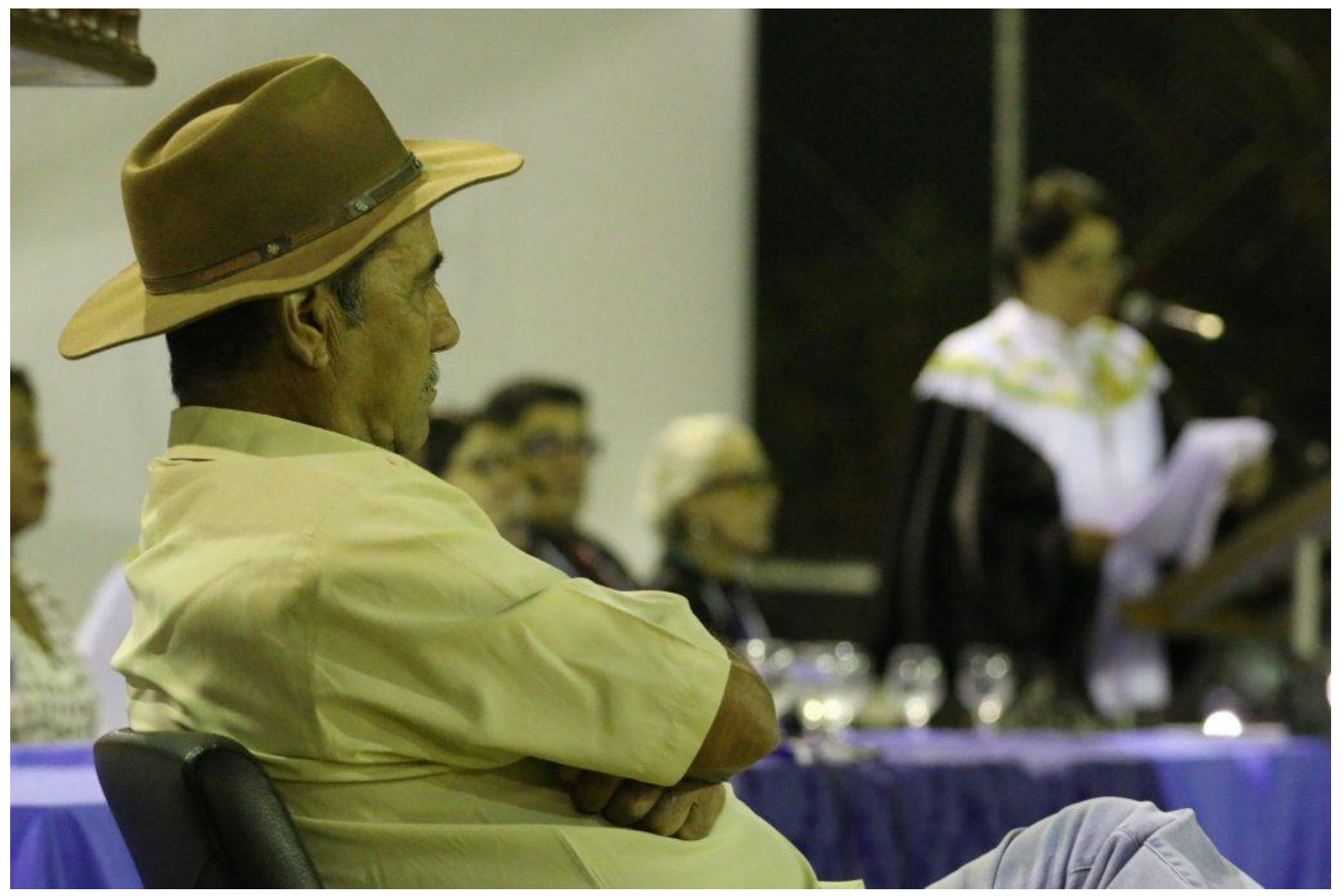

3 Disponível em: <https://unimontes.br/ambientalista-braulino-caetano-recebe-o-titulo-de-honoris-causareconhecimento-ao-trabalho-das-pessoas-simples/> . Acesso em 11 fev. 2021. 
Braulino Caetano dos Santos, Doutor Honoris Causa pela Unimontes: o reconhecimento de um saber que vem das Comunidades Luciene Rodrigues
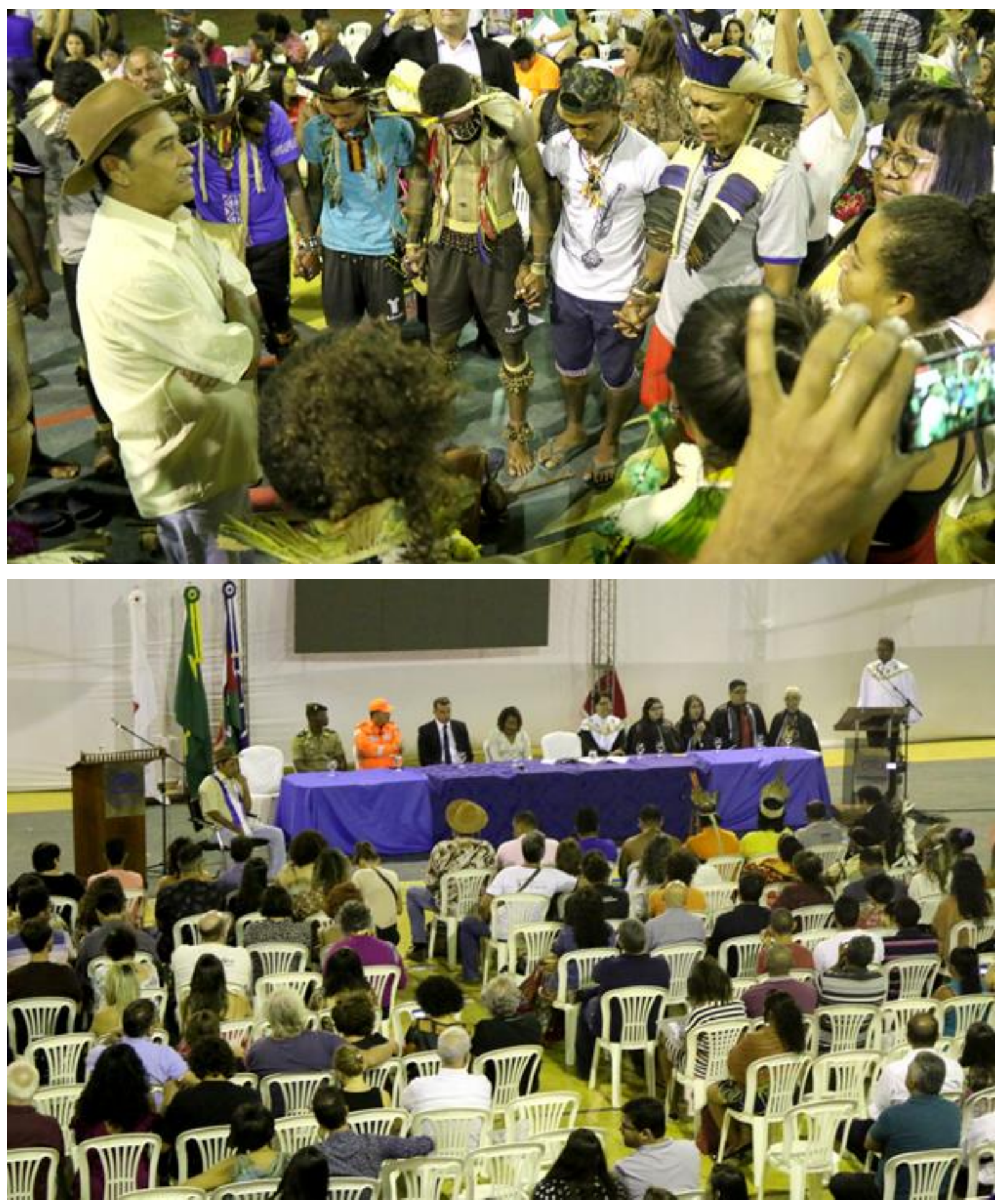

\section{REFERÊNCIAS}

AUGUSTO, Rosely Carlos. Aprender na Prática: Narrativas e histórias de lideranças Camponesas no Sertão, Norte de Minas, nas última três décadas. Belo Horizonte, UFMG, Faculdade de Educação, 2011.

Artigo recebido em: 11 fevereiro de 2021

Artigo aceito em: 02 de março de 2021.

Artigo publicado em: 05 de abril de 2021. 